\title{
Simulation of Rock Infiltration Systems
}

\section{Bruce N. Wilson}

\section{Aleksey Y. Sheshukov}

\section{Aida Mendez}

\author{
Written for presentation at the \\ 2009 ASABE Annual International Meeting \\ Sponsored by ASABE \\ Grand Sierra Resort and Casino \\ Reno, Nevada \\ June 21 - June 24, 2009
}

\begin{abstract}
Rain gardens, infiltration trenches, and dry detention ponds are widely used to treat runoff from construction site and urban watersheds. These infiltration systems have the potential to remove contaminants by filtration, but they also may become clogged with deposited sediment and other debris. An overview of studies done at the University of Minnesota over the past 10 years to investigate the trapping of sediment and the corresponding changes in permeabilities is presented. They include experimental data collected from the laboratory cores, a prototype dry detention basin, and field studies as well as the development of algorithms used in the WATER (Watershed Assessment Tool for Environmental Risk) model.
\end{abstract}

Keywords. Rain garden, infiltration, urban, stormwater

The authors are solely responsible for the content of this technical presentation. The technical presentation does not necessarily reflect the official position of the American Society of Agricultural and Biological Engineers (ASABE), and its printing and distribution does not constitute an endorsement of views which may be expressed. Technical presentations are not subject to the formal peer review process by ASABE editorial committees; therefore, they are not to be presented as refereed publications. Citation of this work should state that it is from an ASABE meeting paper. EXAMPLE: Author's Last Name, Initials. 2009. Title of Presentation. ASABE Paper No. 09----. St. Joseph, Mich.: ASABE. For information about securing permission to reprint or reproduce a technical presentation, please contact ASABE at rutter@asabe.org or 269-429-0300 (2950 Niles Road, St. Joseph, MI 49085-9659 USA). 


\section{Introduction}

Construction activities and urbanization generally result in a reduction in landscape vegetation and an increase in impervious area. These changes increase the volume of stormwater runoff, which can adversely impact the health of streams and other surface water. An increase in stormwater volume also corresponds to a decrease in ground recharge. A decrease in recharge can adversely impact water table levels and ground water flow. Therefore, much interest exists in reducing stormwater runoff by enhanced infiltration systems. Enhanced infiltration systems include the use of vegetal swales and rock and gravel infiltration trenches and basins.

Rock and gravel infiltration systems have the potential to be plugged with sediment and other material in the stormwater runoff. The Department of Bioproducts and Biosystems Engineering at the University of Minnesota has investigated this process in a series of studies over the past 10 years. The purpose of this paper is to summarize these research activities. The activities include the collection of experimental data and the development of predictive algorithms. Only key features of the work are given here.

\section{General considerations}

A general representation of the deposition process for rock and gravel filters is shown in Figure 1. For most storms of interest, the inflow rate is greater than the outflow rate resulting in ponded water. For dry detention ponds, some of the sediment will be deposited on the bottom of the depression before the flow reaches the rock and gravel filters. The processes of deposition in this region of the basin are similar to those of a pipe outlet. Average flow depth and detention times are important factors, both of which are directly related to the permeability of the media. In addition to the direct deposition of sediment on the bottom of the basin, sediment can also be trapped in the media itself. This removal of sediment in the media directly affects its permeability. General predictive algorithms should be able to consider both stages of the deposition process.

In comparison to flow in agricultural soils, specific discharge of flow through rock and gravel media can be quite large, frequently too large to neglect inertia terms in the equation of motion. Specific discharge is then poorly represented by Darcy's equation. Therefore, we used a general form of porous media flow given by McWhorter and Sunada (1981) to predict specific discharges and to measure media permeabilities.

Activities done by the University of Minnesota include both experimental and modeling studies. Experimental studies were conducted using laboratory cores, a prototype dry detention basin, and a field site. The laboratory core data were used to develop two different algorithms for simulating the response of rock and gravel filters to sediment-laden inflows. These algorithms have been implemented in the WATER (Watershed Assessment Tool for Environmental Risk) model (Wilson et al., 2008). One of the algorithms, referred to as the Protocol Method, is based solely on the evaluation of experimental data collected in a laboratory setting. The response of different rock filters is dependent on regression analyses of existing data or from media-specific measurements using standard protocols. The other algorithm, referred to as the Process-Based Method, is based on process-based relationships developed for porous media flow. 


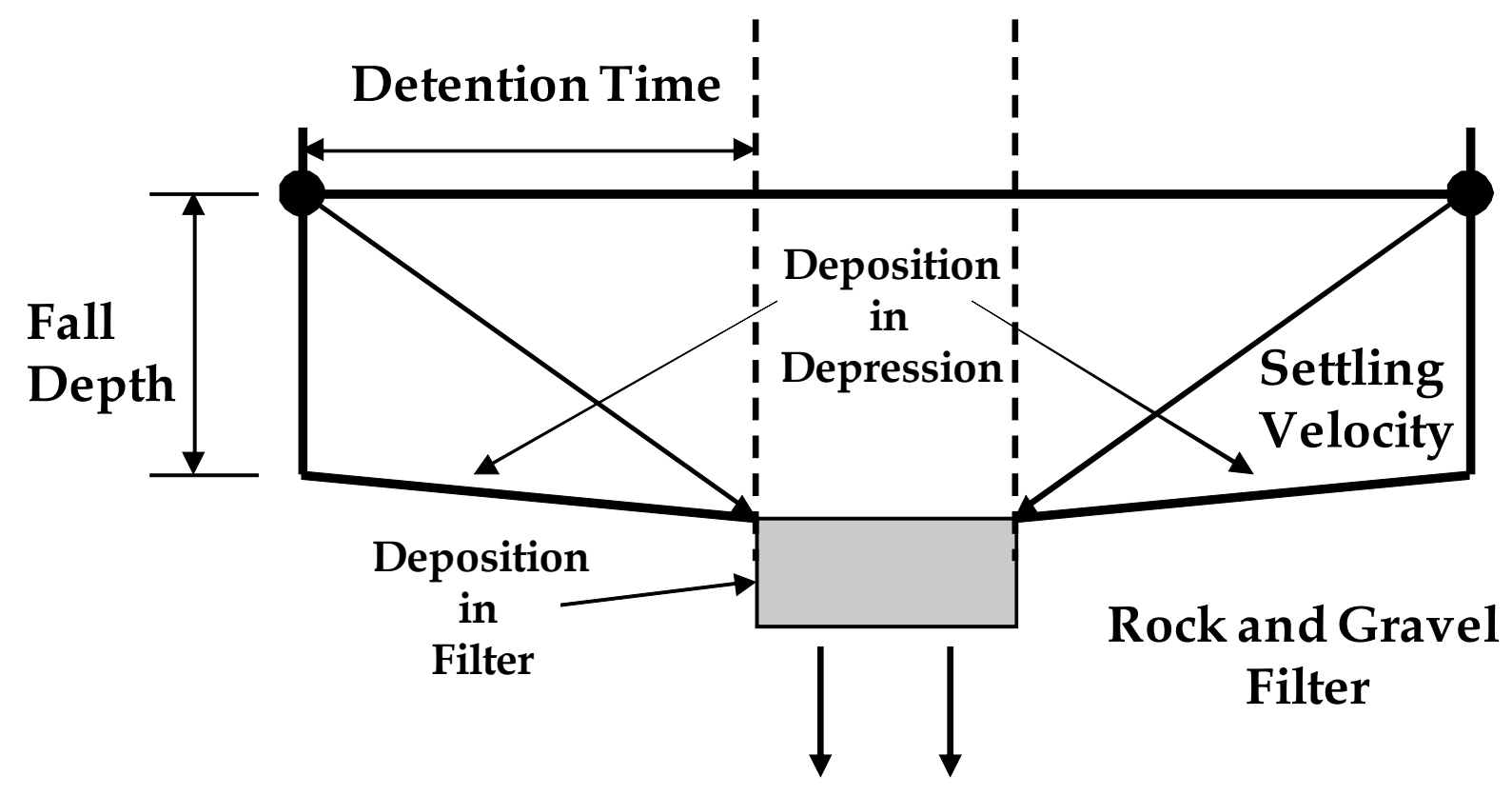

Figure 1. General Representation of Sediment Deposition for Rock and Gravel Filters.

\section{Experimental activities}

\section{Laboratory cores}

Two sets of experimental data were collected using laboratory cores. The first set of experimental data was collected for a study funded by the Minnesota Department of Agriculture (MDOA) (Wilson et al., 1999). Sediment was delivered to a test chamber using a vibrating sloped feeder, the slope of which could be changed to increase or decrease the rate. The maximum rate of sediment delivery for this system was, however, unable to plug the media for the largest rock filter. Water flow was controlled to maintain an approximate constant pressure head. The test chamber was constructed using PVC pipe of $15 \mathrm{~cm}$ inside diameter. A metal mesh was used to support the media at the bottom of the module. The cylinder was filled with media to a depth of approximately $30 \mathrm{~cm}$.

Three different gravel mixtures were used in the test chambers corresponding to fine (Camas \#7), medium (Camas \#67), and coarse (Camas \#6) particle sizes. The gravel was obtained from the Camas Company, which is a large sand and gravel company in the Twin Cities area. The gravel mixtures are therefore readily available and could be used in field installation. The medium mixture was created by mixing particles from Camas \#7 and Camas \#6. The particle size distributions for the three gravel mixtures were determined using standard sieve analysis techniques. Only one type of influent sediment was used for the laboratory experiments. The particle size distributions were obtained using standard sieve and hydrometer methods. 
Porosity and flow rate using clean water were determined prior to the start of the sedimentladen inflow. Sediment-laden flows were then introduced into the core for 10 minutes. Effluent concentrations were obtained at 2-minute intervals. After the media and deposited soil had dried, the 10 -minute runs were repeated until the flow rate was roughly $10 \%$ of that obtained for clean water or until the maximum sediment load rate was used and no change in permeability.

Additional data were collected with a more extensive experimental design done by Kris Oveson as part of her MS work (Oveson, 2001). This project was funded by the Minnesota Pollution Control Agency, the University of Minnesota Water Resources Center, and the University of Minnesota Agricultural Experiment Station. The impact of three variables was considered in her experimental design: media size, sediment size, and sediment loading rate. The experimental procedures were similar to those of the MDOA's study. Each rock core was constructed from $15 \mathrm{~cm}$ diameter PVC pipe with a metal mesh or screen installed at the bottom of the pipe to support the test media. The core was filled with media to a total depth of $33 \mathrm{~cm}$. A brassbarred reducer was installed in each core approximately $1 \mathrm{~cm}$ above the rock media.

An important difference from the MDOA's study was the sediment feeder apparatus. A conveyor belt system was used to deliver sediment to the core. This system allowed large influent concentrations to be delivered to the cores. During each 10-minute run of a test, four effluent $250 \mathrm{ml}$ samples were collected to determine the effluent sediment concentrations. At the end of the 10-minute run, the four samples were combined to determine an average effluent concentration for that 10 minutes of the test. Each test lasted from 20 to 60 minutes

Three rock media sizes were investigated, referred to as University of Minnesota Standard (UMS) \#1, UMS \#2 and UMS \#3. These rock media varied more than those used in the MDOA's study. Four different types of sediment were investigated. Based on the primary particle sizes, they were classified as a fine sand, two types of silt loams, and a clay. Tests were originally planned to be conducted until the permeability of the rock core was less than $10 \%$ of its clean water value. After the test, the rock core was placed in a drying oven to determine the total mass of sediment deposition.

\section{Prototype basin}

The prototype basin was constructed, and tests were performed at the St. Anthony Falls Laboratory as part of the Minnesota Department of Agriculture's project (Wilson et al., 1999). The dimensions of the prototype basin was selected to correspond to expected field values of the Peclet number, the Hazen number and dimensionless momentum ratio (Wilson et al., 1990)

Inflow into the prototype basin was obtained by combining water from the Mississippi River with sediment in a mixing tank. Sediment-laden flow was then pumped from the mixing tank to a PVC pipe that was supported around circumference of the prototype basin. Thirty-two orifice holes were used to ensure a uniform distribution of sediment-laden flows into the system. At the middle of the basin, a section of the bottom was removed and used to evaluate different types of rock and gravel mixtures. 
Changes in permeability with time were estimated using observed changes in the outflow rate. Effluent concentration, total sediment deposition in the depression, and deposition in the rock media itself were measured to determine the performance of different rock media.

\section{Field studies}

In addition to her laboratory core work, Oveson (2001) also investigated the performance of rock and gravel filters at a field site. This work was done at the Southern Research and Outreach Center in Waseca, MN. A field of a 1.2 ha (3 acre) was divided into four adjacent areas of approximately 0.3 ha $(0.74$ acre $)$ each. The runoff from each of the areas was directed to dry detention basin for the evaluation of different types of rock and gravel filters. Most of the soils in the fields are a Webster silt clay loam. During her study, the area was planted in beans with rows running up-and-down slope to maximize runoff for the study.

To simulate field depressions, rectangular basins were constructed at the bottom of the runoff from each field. Each basin had a surface area of 0.02 ha (0.051 acre). The range in flow depth varied by $30 \mathrm{~cm}$ ( $1 \mathrm{foot}$ ) between the center and edge of the basin and its. Four different types of outlets from the basins were examined: a $15 \mathrm{~cm}$ (6-inch) flush drain pipe, a rock inlet of course gravel, a rock inlet of fine gravel or pea rock, and a rock inlet filled with a 50/50 mixture of the course and fine gravel.

To monitor the response of the different types of filters, a 1.2 meter $(4 \mathrm{ft})$ diameter corrugated pipe was vertically installed to an approximate depth of 1.8 meters $(6 \mathrm{ft}$ ) below ground level, to serve as a manhole. Each manhole is directly in line with the $20 \mathrm{~cm}(8 \mathrm{in})$ drainpipe. The manholes will serve as a data collection site. A second $20 \mathrm{~cm}$ (8 in) subsurface drainpipe 6 meters $(20 \mathrm{ft})$ in length exits the manhole and carries water east to the drainage ditch.

\section{Modeling activities}

\section{Protocol method}

One of the rock and gravel filters algorithms developed at the University of Minnesota is called the Protocol Method. This method is based on experimentally-derived parameters using a standard protocol. The protocol currently available corresponds to the experimental steps used by Oveson's (Oveson, 2001). However, additional work may be needed to fine-tune her experimental approach.

The Protocol Method is based on the assumption that the user can send the rock or gravel media of interest to laboratory. The laboratory would perform a series of flow rate tests for clean water and sediment-laden flows with different influent sediment size to obtain the parameters for the Protocol Method. These parameters are used to simulate the response of the filter in the field. Parameters that need to be measured by the standard protocol are porosity, clean media permeability, inflow mass at 70\% reduction in clean media permeability, and overall trap efficiency for this inflow mass. If users do not have the resources to perform a series of tests for their media, the WATER model has the option of estimating these parameters 
from easy-to-obtain characteristics of the media. Parameters are then obtained from regression equations developed from the laboratory core data.

Details of Protocol Method and its implementation into the WATER model are given by Wilson et al. (2008).

\section{Process-based approach}

In addition to the Protocol Method, a Process-Based Method was also developed to simulate the response of rock and gravel filters. The Process-Based Method uses a process-based framework to predict sediment deposition in filters. The framework is based on a pore-scale model for determining specific discharge by integrating the flow in different size pores. With sediment deposition, the number of pores and the size of pores are allowed to change. A fractal model is used to represent the initial characteristics of the media and changes with sediment deposition. Trap efficiency of the media was developed from well established theories to understand porous media processes by chemical and waste-water engineers. The ProcessBased Method has several parameters. These parameters were estimated by obtaining the best fit possible with the laboratory core experimental data.

Details of Protocol Method and its implementation into the WATER model are given by Wilson et al. (2008).

\section{Conclusion}

Infiltration systems are widely used to reduce the stormwater from urban areas and construction sites. Although these systems have the potential to remove contaminants by filtration, they can plug with deposited sediment and other debris. We have provided a brief summary of the experimental and modeling work done over the past 10 years by the Department of Bioproducts and Biosystems Engineering at the University of Minnesota. Details of the study are contained in technical reports.

Laboratory, proto-type and field studies were conducted to gather experimental information on the response of different types of rock media. The laboratory studies were used to gather information on the basic processes. The proto-type and field studies were conducted to evaluate the usefulness of these laboratory-derived parameters. Two different algorithms were also developed to simulate the response of rock and sand filters. Both of these algorithms have been implemented in the WATER (Watershed Assessment Tool for Environmental Risk) model.

\section{References}

Oveson, K.L. 2001. Evaluation and Design of Rock Inlets as an Alternative Form of Surface Drainage. M.S. Thesis, University of Minnesota, Graduate School, Minneapolis, MN.

Wilson, B.N., H.V. Nguyen, U.B. Singh, S. Morgan, P. Van Buren, D. Mickelson, E. Jahnke, and B. Hansen. 1999. Evaluation of alternative designs for surface tile inlets using prototype studies. Final Report, Minnesota Department of Agriculture, St. Paul, MN, Contract number 417121 
Wilson, B.N., A.Y. Sheshukov, and A. Mendez. 2008. Design Tool for Controlling Runoff and Sediment from Highway Construction. Final Report for Contract: MN/RC 2008-3, Minnesota Department of Transportation, 395 John Ireland Boulevard, Mail Stop 330, St. Paul, Minnesota 55155 